\title{
Common urological problems in children: primary nocturnal enuresis
}

\author{
Ivy HY Chan, Kenneth KY Wong *
}

\section{A B S T R A C T}

Enuresis is a common complaint in children, with a prevalence of around $15 \%$ at age 6 years. Evidence suggests that enuresis could affect neuropsychiatric development. The condition may represent an entire spectrum of underlying urological conditions. It is important to understand the difference between monosymptomatic and non-monosymptomatic enuresis. Primary monosymptomatic enuresis can be managed efficaciously with care in different settings, like primary care, specialist nursing, or paediatric specialists, while non-monosymptomatic enuresis
The diagnosis, investigation, and management of the two types of enuresis are discussed in this review.

\section{Hong Kong Med J 2019;25:305-11 \\ https://doi.org/10.12809/hkmj197916}

IHY Chan, MB, BS, FHKAM (Surgery)

KKY Wong *, PhD, FHKAM (Surgery)

Department of Surgery, The University of Hong Kong, Pokfulam, Hong Kong

requires more complex evaluation and treatment. * Corresponding author: kkywong@hku.hk

\section{Introduction}

Enuresis is a common problem in children worldwide. Despite this, many parents underestimate its impact. The reactions from parents of children with enuresis are diverse, with various misconceptions among patients and parents. ${ }^{1}$ Some parents delay seeking medical assessment to avoid stigmatisation. Many parents believe that enuresis will be cured with age and does not need any treatment. Yet, left untreated, this problem may persist into adulthood. ${ }^{2}$

The most common enuresis condition is primary monosymptomatic nocturnal enuresis (PMNE). It can also be a symptom of other urological conditions like detrusor overactivity, neurogenic bladder, or posterior urethral valve.

The underlying causes of PMNE and nonmonosymptomatic nocturnal enuresis are different. Their treatment and prognosis thus differ. Both conditions nonetheless can affect patients' psychological development, self-confidence, and participation in social events.

\section{What is enuresis?}

The term 'enuresis' refers to nocturnal urinary incontinence, while urinary incontinence is involuntary leakage of urine. This differentiation is very important in establishing diagnosis and hence formulating treatment plans. The American Psychiatric Association defines enuresis as recurrent urine leakage in bed $>2$ nights per week for $>3$ weeks in patients aged $\geq 5$ years.

In contrast, PMNE refers to those patients who have never been dry for $>6$ months and have urinary leakage during sleep time only. They do not have any other urinary symptoms like daytime urinary leakage, urinary frequency, or urgency. Hence, patients with symptoms in addition to isolated bedwetting warrant different evaluation and should be regarded as having non-monosymptomatic nocturnal enuresis. The International Children Continence Society (ICCS) has listed the definitions of different terminology for all related symptoms and signs $\left(\mathrm{Table}^{3}\right)$.

\section{Prevalence}

The prevalence of enuresis in children is usually quoted as $10 \%$ to $15 \%$ at age 6 years, $5 \%$ at age 10 years, and $0.5 \%$ to $1 \%$ among teenagers/young adults. ${ }^{4}$ A large-scale epidemiological study in Hong Kong carried out in 2006 showed the prevalence of nocturnal enuresis as $16.1 \%$ at age 5 years, $3.14 \%$ at age 9 years, and $2.2 \%$ at age 19 years. ${ }^{5}$ It is more common in boys in all age-groups. The prevalence of nocturnal enuresis decreases as age increases. However, patients who have daytime urinary incontinence and those with enuresis $>3$ nights per week seem to have symptoms that persist to adulthood, according to a 2004 study that showed the static prevalence of enuresis over different age-groups from age 16 to 40 years. ${ }^{6}$ Thus, the phenomenon of 'growing out of enuresis' may not apply in all patients.

\section{Aetiology and risk factors}

Enuresis is a complex condition to which genetic, physiological, and psychological factors contribute. Some patients have a definite cause of enuresis or urinary incontinence, like neurogenic bladder, 


\section{常見的小兒泌尿系統問題：原發性夜間遺尿症 陳巧兒、黃格元}

遺尿症是兒童常見的問題。在6歲時患病率約為 $15 \%$ 。證據表明遺尿有 可能影響精神發育。這種情況亦可能代表整個潛在泌尿疾病的領域。 了解單一症狀與非單一症狀遺尿症之間的區別非常重要。原發性單一 症狀遺尿症可以在不同環境中得到有效治療, 比如家庭科、專科護士 或兒科專家。非單症狀性遺尿症則需要更複雜的評估和治療。本綜述 討論兩種遺尿症的診斷、調查和管理。 detrusor overactivity, vaginal reflux, or stress incontinence. Presence of daytime symptoms definitely warrants a detailed investigation. it has been hypothesised that small bladder volume in children plays a role in PMNE. Nonetheless, further studies showed that there was a genetic component to this condition. Indeed, a Finnish twin study showed a higher concordance rate of enuresis for monozygotic than dizygotic twins. ${ }^{7}$ Furthermore, there is a strong association with parental history of childhood enuresis. ${ }^{8}$ In this study, the overall odds ratio of having nocturnal enuresis and urinary incontinence was 10.1 times higher if the father or mother also had a history of nocturnal enuresis or urinary incontinence.

It is also known that antidiuretic hormone, or vasopressin, is very important in controlling and concentrating the urine volume. The normal physiological increase in night-time vasopressin level/diurnal level has been shown to be absent in some enuretic children. ${ }^{9,10}$ There is a phenomenon of 'nocturnal polyuria', characterised by increased nocturnal urine output due to a dysregulated diurnal rhythm of antidiuretic hormone, with a larger volume of urine production at night time. ${ }^{11}$ Adults with nocturnal polyuria syndrome will need to get up to urinate a few times every night. This group of children will benefit from desmopressin treatment.

Enuresis is classified as a sleep disorder by the American Psychiatric Association in the fifth edition of the Diagnostic and Statistical Manual of Mental Disorders. Enuresis is correlated with the quality of sleep and the arousability of the child. Poor sleep quality, periodic movement during sleep, and inadequate sleep are factors associated with enuresis and night-time diuresis. ${ }^{12,13}$ The awareness of the relationship between enuresis and obstructive sleep apnoea is also increasing. ${ }^{13}$ In 2014 , Kovacevic et $\mathrm{al}^{14}$ showed resolution of nocturnal enuresis after

TABLE. List of terminology by International Children Continence Society ${ }^{3}$

\begin{tabular}{|c|c|}
\hline \multicolumn{2}{|l|}{ Storage symptoms } \\
\hline Increased or decreased voiding frequency & $<3$ or $>8$ times per day \\
\hline Urinary incontinence & Involuntary leakage of urine \\
\hline Continuous incontinence & Constant urine leakage (day and night) \\
\hline Intermittent incontinence & Leakage of urine in discrete amounts \\
\hline Daytime incontinence & Intermittent incontinence that occurs while awake \\
\hline Enuresis & Intermittent incontinence that occurs exclusively during sleeping periods \\
\hline Daytime incontinence and enuresis & Combined intermittent incontinence during "awake" periods and while sleeping \\
\hline Urgency & Sudden and unexpected experience of an immediate and compelling need to void \\
\hline Nocturia & The need to wake at night to void \\
\hline \multicolumn{2}{|l|}{ Voiding symptoms } \\
\hline Hesitancy & Difficulty initiating voiding when the child is ready to void \\
\hline Straining & $\begin{array}{l}\text { An intense effort to increase intra-abdominal pressure (eg, Valsalva manoeuvre) to initiate and } \\
\text { maintain voiding }\end{array}$ \\
\hline Weak stream & An observed stream or uroflow that is weak \\
\hline Intermittency & Micturition that is not continuous but rather has several discrete stops and start spurts \\
\hline Dysuria & Complaint of burning or discomfort during micturition \\
\hline \multicolumn{2}{|l|}{ Others } \\
\hline Holding manoeuvres & Observable strategies used to postpone voiding or suppress urgency \\
\hline Feeling of incomplete emptying & Complaint that the bladder does not feel empty after voiding \\
\hline Urinary retention & $\begin{array}{l}\text { Sensation of an inability to void despite persistent effort in the presence of a fully distended } \\
\text { bladder }\end{array}$ \\
\hline Post micturition dribble & Involuntary leakage of urine immediately after voiding has finished \\
\hline Spraying (splitting) of the urinary stream & Urine passes as a spray or a split rather than a single discrete stream \\
\hline
\end{tabular}


adenotonsillectomy. Indeed, a systematic review on this topic also showed that after adenotonsillectomy, an improvement of nocturnal enuresis was seen in $>60 \%$ of patients, with a complete resolution rate in excess of $50 \%{ }^{15}$

There is also strong association between attention deficit hyperactivity disorder (ADHD) and enuresis. Children with enuresis had 2.88 times increased odds of having ADHD compared with those without enuresis in a population study in the United States. ${ }^{16}$ Conversely, children with ADHD have also been shown to have a 2.1 times higher risk of enuresis. ${ }^{17}$ In addition, treating ADHD with medications like atomoxetine can decrease the number of wet nights in children with co-morbid enuresis. ${ }^{18}$

Until now, no conclusions about the causal relationship between enuresis and childhood behavioural problems could be drawn. Yet, patients with refractory enuresis may warrant neuropsychiatric evaluation. ${ }^{19}$

\section{Why do we need to treat enuresis?}

The prevalence of enuresis decreases with age. Parents may therefore ask whether enuresis really needs to be treated. The answer is yes because, first, enuresis is a symptom but not a diagnosis. After specialist medical assessment, other underlying urological problems may be suspected and further investigations instigated. Second, enuresis is often associated with poor school performance and decreased quality of life, self-esteem, and psychosocial development. ${ }^{19,20}$ A study showed significant improvement in self-esteem with higher self-concept scores after 6 months of treatment with desmopressin or alarm therapy. ${ }^{21}$ Finally, enuresis can persist to adulthood if not treated properly.

About one third of the patients with childhood enuresis reported symptoms of nocturia despite resolution of enuresis. About one quarter of them still reported some kind of urinary incontinence.

\section{Initial assessment and evaluation}

Detailed history taking is the key to success in treating enuresis or urinary incontinence. Bladder function and cognitive control of voiding take time to develop. By definition, we define enuresis as persistent urinary incontinence in children aged $>5$ years. Before the detailed history, there are three important questions that one should ask (Fig).

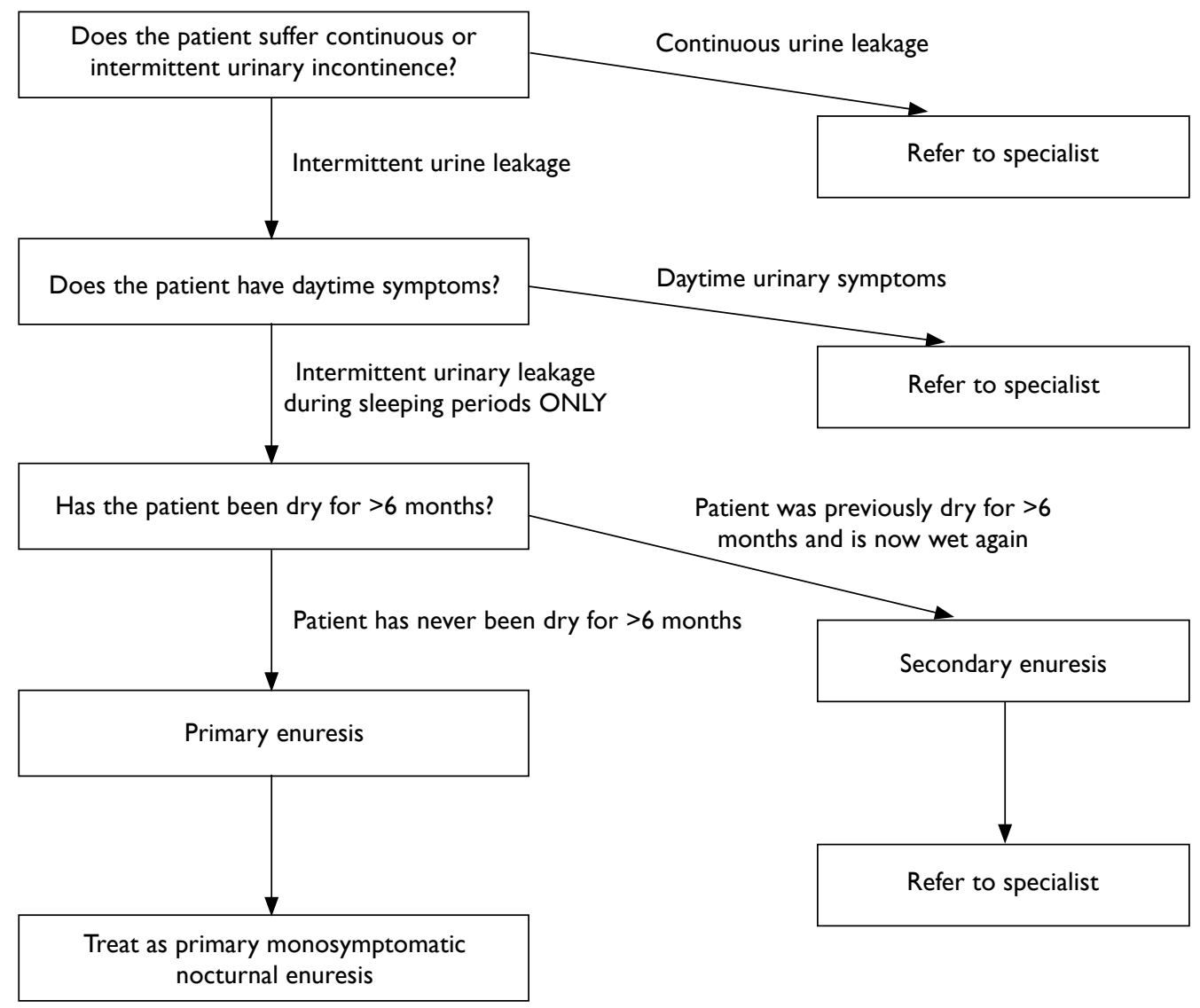

FIG. Diagnostic flow for a paediatric patient aged $\geq 5$ years with urinary incontinence 


\section{Does the patient suffer continuous or intermittent urinary incontinence?}

'Intermittent incontinence' is discrete leakage of urine, whereas 'continuous incontinence' is constant urine leakage (both day and night time). Patients with continuous urinary incontinence usually have congenital anatomical anomalies, eg, ectopic ureter, exstrophy variant, etc. These patients will need to be referred to a specialist for further assessment.

\section{Does the patient have daytime symptoms?}

Enuresis per se is simply involuntary leakage of urine at night time. If patients have symptoms like excessive daytime urinary frequency (urination $>8$ times/day), urinary urgency (sudden and unexpected experience of an immediate and compelling need to void), daytime urinary incontinence (urine leakage during the awake period), interrupted urine stream, hesitancy, weak urine stream, or other lower urinary tract symptoms, they should be referred to a specialist for further assessment. The list of symptoms, terminology, and definitions is described in the Table. ${ }^{3}$

\section{Is this 'primary enuresis'?}

Primary enuresis is defined by the ICCS as a patient not having been dry for $>6$ months. If the patient has been dry for $>6$ months and then has enuresis again, it is termed secondary, and the patient should be referred to a specialist for further assessment.

\section{History taking}

The aim of history taking is to formulate a correct diagnosis. As mentioned above, it is important to see whether the patient has PMNE. If not, the patient may have other conditions like detrusor overactivity or neurogenic bladder, which may need referral for further investigation and management. The management of this group of patients is out of the scope of this review. Questions asked during history taking should also help to exclude underlying neurological or anatomical anomalies. Information about bowel function and constipation should be obtained, as should a brief assessment of psychological history. The following aspects should be asked.

\section{Urinary symptoms}

The following symptoms of urinary storage and emptying are important.

1. Night-time symptoms: Frequency of bedwetting (times/week), precipitating factors for wetting (eg, long holiday/sleep hours, drinking before bed). This is used to identify the severity of bedwetting.
2. Daytime symptoms: Voiding frequency in daytime (times/day), sudden urgent need to void, habit of voiding postponement, holding manoeuvres (tips of heel pressing on perineum, leg crossing), abdominal straining to void, and interrupted urine stream.

3. Urinary frequency of 3 to 8 times per day is defined as normal by the ICCS. If it is out of this range, the patient may have other problems. The presence of other daytime symptoms may signify that the patient is having non-monosymptomatic enuresis.

History taking of urinary or voiding symptoms is often difficult in a child. Adequate time and patience in out-patient clinics are therefore absolutely necessary. The use of a bladder diary and enuresis chart is helpful in providing vital information, such as bladder capacity and the presence of urinary leakage, and helps to identify underlying bladder dysfunction.

\section{Bowel symptoms}

The frequency of bowel movements and the presence of faecal incontinence should be asked. Bladder and bowel movements are closely related. Constipation affects the treatment of enuresis: it is often difficult to completely stop enuresis in a patient with chronic constipation. Faecal incontinence can also be a symptom of constipation or underlying spinal cord anomalies. $^{22}$

\section{Drinking habits}

The quantity and quality of drinking during the day and fluid intake in the evening are important. Evidence of diabetes insipidus may be obtained from this element of history. With heavy workloads and tight school schedules in Hong Kong, many patients do not have adequate fluid intake during daytime. They prefer to drink in the evening. It is logical to deduce that a large volume of fluid intake in the evening increases the risk of enuresis. Patients should also be advised to void before bed. A bladder diary is a vital instrument for the patient and parents to monitor fluid intake and observe voiding habits. This diary is shown to the clinician during clinic visits for progress monitoring.

\section{Possible underlying problems and general medical health}

These symptoms include: (a) history of urinary tract infections, (b) known urological or spinal cord problems, (c) evidence of ADHD, autism, or other psychological problems, (d) history of motor development or learning disability, (e) sleep habits, sleep quality and presence of heavy snoring, and (f) family history, living environment, or evidence of sexual abuse. 


\section{Physical examination}

A general physical examination including body weight and height can help to identify patients with growth retardation or failure to thrive, which may be suggestive of an underlying disorder. An abdominal examination can reveal faecal impaction. Examination of the genitalia and inspection of underwear can identify signs of sexual abuse, stress incontinence, or faecal incontinence. Dimples or hair tufts in the lumbosacral area may be caused by occult spinal dysraphism.

A simple urine dipstick test may be helpful when diabetes mellitus or urinary tract infection is suspected.

\section{Management of primary monosymptomatic nocturnal enuresis}

Once the diagnosis of PMNE is made, advice and treatment should be given accordingly. The patient and parents should be educated about the prevalence of enuresis in children and the importance of treatment. They should know that enuresis is common and that the child should not be blamed or labelled as lazy. Yet, they should understand that indolent psychological stress may result if the problem is not dealt with seriously.

\section{Discussion and general advice}

The child should be advised to avoid large amounts of fluid intake at least 1 to 2 hours before bed, avoid heavy loads of salt and protein during dinner time, void before bed, and drink adequately during daytime. Understanding of the patient's drinking, voiding, and eating habits is important to treatment adherence and hence success. It is ideal to keep records on an enuresis chart to illustrate the frequency of the enuresis and a bladder diary for possible daytime symptoms. Sometimes it is difficult or unreliable for the patient or caretaker to recall the pattern of enuresis; keeping a calendar of bed wetting nights should help to monitor treatment progress. Rewards can also be given for dry nights.

\section{Constipation}

Urinary and bowel functions are closely related. Children with functional constipation are 6.8 times more likely to have lower urinary tract symptoms, and these patients have higher Voiding Dysfunction Symptom Scores. ${ }^{23}$ The rate of constipation is also much higher in children with urinary incontinence. After treating the constipation, urinary incontinence improves, especially in adolescents. ${ }^{24}$ Bowel habits should be asked, and daily passage of soft stool without discomfort should be the aim. Principles of treatment should include a four-step approach:
Education, dis-impaction of faeces, prevention of re-accumulation, and follow-up. ${ }^{25}$ Advice on fluid intake, fibre intake, and use of laxatives are the common first-line treatment options. A metaanalysis from the Cochrane library showed good results of using polyethylene glycol on paediatric patients with functional constipation. ${ }^{26}$

\section{Alarm therapy}

Enuresis alarms are an effective measure to improve or cure bedwetting. This is a behavioural therapy that works by conditioning on arousal. The rationale is to wake up the child with the alarm once the sensor attached to the child's pants is wet. The child will thus gradually learn to wake up before wetting the bed. This requires the patient to wake up, cease voiding in bed, go to void in the toilet, and reattach the alarm when they return. In a 2005 metaanalysis, about two thirds of the children became dry during the treatment period, and nearly half who persisted with alarm use remained dry after treatment finished. ${ }^{27}$ Its effect is similar to the use of desmopressin. ${ }^{28,29}$ However, its long-term success rate is significantly higher than that of desmopressin, with $68.8 \%$ of one study's patients who used enuresis alarms continuing to have dry nights, whereas only $46 \%$ of the desmopressin group did. ${ }^{29}$

The ICCS recommends that the parent or caregiver attend the child each time the alarm rings to make sure the child does not just turn the alarm off to maximise the effect..$^{30}$ As with other behavioural therapies, this is not an immediate cure. It requires a trial of a minimum of 2 to 3 months and requires compliance from the child and family. Despite the promising long-term success rate of enuresis alarms, the initial dropout rate can be up to $30 \%{ }^{29}$ This is probably caused by the awkwardness of using the alarm and the sleep disruption to the whole family. The ICCS also recommends that the patient be reviewed on the first day of using the alarm and 2 to 3 weeks after starting use of the alarm to improve compliance.

\section{Desmopressin}

Desmopressin is a synthetic analogue of arginine vasopressin antidiuretic hormone. It acts on the renal tubules to concentrate urine. It has been hypothesised that loss of diurnal rhythm of vasopressin is associated with enuresis in children. In the clinical setting, desmopressin can rapidly decrease the number of wet nights. ${ }^{31}$ It has been reported that up to $70 \%$ of patients have dry nights after treatment; yet, $50 \%$ of the "successful" patients reported relapse after stopping the medication. ${ }^{32}$ Gradual withdrawal of desmopressin is thus advocated to help reduce the relapse rate..$^{33}$ Functional bladder capacity has also been shown to predict the response to desmopressin. Patients with functional bladder capacity $>70 \%$ of 
predicted bladder capacity were 2 times more likely to respond to desmopressin. ${ }^{34}$

Desmopressin can be prescribed as tablet or melt (oral lyophilisate) formulation. It should be taken around 1 hour before sleep. The melt preparation can help to further decrease fluid intake before bed $^{35}$ : the patient should be instructed not to drink any fluid after the medication until the next morning.

According to ICCS recommendations, the effects of desmopressin can be evaluated after 2 to 6 weeks with an enuresis diary. ${ }^{36}$ If there is significant improvement, treatment can be continued to a maximum of 3 months. If the patient does not respond well, re-evaluation of symptoms and diagnosis and referral to a specialist may be needed.

\section{Treatment resistance and other treatment options}

Apart from enuresis alarms and desmopressin, there are other second-line treatment options, but these should ideally be initiated at the specialist level. It is important to ensure that the patient is using the enuresis alarm correctly or taking desmopressin daily before proceeding to second-line treatments. Inability to adhere to the advice of limiting evening fluid or voiding before bed can also decrease the overall treatment success rate.

For those patients who respond poorly to the treatment, re-evaluation should be considered. Questions about bowel habits and psychiatric conditions should be asked, and a full urine frequency/volume chart should be recorded. Referral to specialists should also be considered.

Second-line treatment options include combination therapy using both enuresis alarm and desmopressin, use of tricyclic antidepressants, indomethacin, and even daytime diuretics.

\section{Conclusion}

Primary monosymptomatic nocturnal enuresis is a common condition that can impair a child's psychosocial development. Affected children and caretakers should be educated about its prevalence, potential associated problems, associated comorbidities, and the necessity of treatment. It should be distinguished from non-monosymptomatic nocturnal enuresis. Advice about drinking and voiding habits, use of enuresis alarms, and desmopressin are common treatment options. Patients with poor response to treatment should be referred to specialists for re-evaluation.

\section{Author contributions}

Concept or design: All authors.

Acquisition of data: IHY Chan.

Analysis or interpretation of data: All authors.
Drafting of the article: IHY Chan.

Critical revision for important intellectual content: KKY Wong.

\section{Conflicts of interest}

As an editor of the journal, KKY Wong was not involved in the peer review process. The other author has no conflicts of interest to disclose.

\section{Funding/support}

This research received no specific grant from any funding agency in the public, commercial, or not-for-profit sectors.

\section{References}

1. Cederblad M, Nevéus T, Åhman A, Österlund Efraimsson E, Sarkadi A. "Nobody asked us if we needed help": Swedish parents experiences of enuresis. J Pediatr Urol 2014;10:749.

2. Goessaert AS, Schoenaers B, Opdenakker O, Hoebeke P, Everaert K, Vande Walle J. Long-term followup of children with nocturnal enuresis: increased frequency of nocturia in adulthood. J Urol 2014;191:1866-70.

3. Austin PF, Bauer SB, Bower W, et al. The standardization of terminology of lower urinary tract function in children and adolescents: update report from the standardization committee of the International Children's Continence Society. Neurourol Urodyn 2016;35:471-81.

4. Franco I, von Gontard A, De Gennaro M; International Children's Continence Society. Evaluation and treatment of nonmonosymptomatic nocturnal enuresis: a standardization document from the International Children's Continence Society. J Pediatr Urol 2013;9:23443.

5. Yeung CK, Sreedhar B, Sihoe JD, Sit FK, Lau J. Differences in characteristics of nocturnal enuresis between children and adolescents: a critical appraisal from a large epidemiological study. BJU Int 2006;97:1069-73.

6. Yeung CK, Sihoe JD, Sit FK, Bower W, Sreedhar B, Lau J. Characteristics of primary nocturnal enuresis in adults: an epidemiological study. BJU Int 2004;93:341-5.

7. Hublin C, Kaprio J, Partinen M, Koskenvuo M. Nocturnal enuresis in a nationwide twin cohort. Sleep 1998;21:57985.

8. von Gontard A, Heron J, Joinson C. Family history of nocturnal enuresis and urinary incontinence: results from a large epidemiological study. J Urol 2011;185:2303-6.

9. Nørgaard JP, Pedersen EB, Djurhuus JC. Diurnal antidiuretic-hormone levels in enuretics. J Urol 1985;134:102931.

10. Rittig S, Knudsen UB, Nørgaard JP, Pedersen EB, Djurhuus JC. Abnormal diurnal rhythm of plasma vasopressin and urinary output in patients with enuresis. Am J Physiol 1989;256(4 Pt 2):F664-71.

11. Rittig S, Schaumburg HL, Siggaard C, Schmidt F, Djurhuus JC. The circadian defect in plasma vasopressin and urine output is related to desmopressin response and enuresis status in children with nocturnal enuresis. J Urol 2008;179:2389-95.

12. Dhondt K, Raes A, Hoebeke P, Van Laecke E, Van Herzeele C, Vande Walle J. Abnormal sleep architecture and refractory nocturnal enuresis. J Urol 2009;182(4 Suppl):1961-5. 
13. Alexopoulos EI, Malakasioti G, Varlami V, Miligkos M, Gourgoulianis K, Kaditis AG. Nocturnal enuresis is associated with moderate-to-severe obstructive sleep apnea in children with snoring. Pediatr Res 2014;76:555-9.

14. Kovacevic L, Wolfe-Christensen C, Lu H, et al. Why does adenotonsillectomy not correct enuresis in all children with sleep disordered breathing? J Urol 2014;191(5 Suppl):15926.

15. Lehmann KJ, Nelson R, MacLellan D, Anderson P, Romao $\mathrm{RL}$. The role of adenotonsillectomy in the treatment of primary nocturnal enuresis in children: a systematic review. J Pediatr Urol 2018;14:53.e1-8.

16. Shreeram S, He JP, Kalaydjian A, Brothers S, Merikangas KR. Prevalence of enuresis and its association with attention-deficit/hyperactivity disorder among U.S. children: results from a nationally representative study. J Am Acad Child Adolesc Psychiatry 2009;48:35-41.

17. Mellon MW, Natchev BE, Katusic SK, et al. Incidence of enuresis and encopresis among children with attentiondeficit/hyperactivity disorder in a population-based birth cohort. Acad Pediatr 2013;13:322-7.

18. Ohtomo Y. Atomoxetine ameliorates nocturnal enuresis with subclinical attention-deficit/hyperactivity disorder. Pediatr Int 2017;59:181-4.

19. Gulisano M, Domini C, Capelli M, Pellico A, Rizzo R. Importance of neuropsychiatric evaluation in children with primary monosymptomatic enuresis. J Pediatr Urol 2017;13:36.e1-6.

20. Theunis M, Van Hoecke E, Paesbrugge S, Hoebeke P, Vande Walle J. Self-image and performance in children with nocturnal enuresis. Eur Urol 2002;41:660-7.

21. Longstaffe S, Moffatt ME, Whalen JC. Behavioral and selfconcept changes after six months of enuresis treatment: a randomized, controlled trial. Pediatrics 2000;105(4 Pt 2):935-40.

22. Rasquin A, Di Lorenzo C, Forbes D, et al. Childhood functional gastrointestinal disorders: child/adolescent. Gastroenterology 2006;130:1527-37.

23. Sampaio C, Sousa AS, Fraga LG, Veiga ML, Bastos Netto JM, Barroso U Jr. Constipation and lower urinary tract dysfunction in children and adolescents: a populationbased study. Front Pediatr 2016;4:101.

24. Hodges SJ, Anthony EY. Occult megarectum-a commonly unrecognized cause of enuresis. Urology 2012;79:421-4.

25. Burgers RE, Mugie SM, Chase J, et al. Management of functional constipation in children with lower urinary tract symptoms: report from the Standardization Committee of the International Children's Continence Society. J Urol 2013;190:29-36.

26. Gordon M, MacDonald JK, Parker CE, Akobeng AK, Thomas AG. Osmotic and stimulant laxatives for the management of childhood constipation. Cochrane Database Syst Rev 2016;(8):CD009118.

27. Glazener CM, Evans JH, Peto RE. Alarm interventions for nocturnal enuresis in children. Cochrane Database Syst Rev 2005;(2):CD002911.

28. Perrin N, Sayer L, While A. The efficacy of alarm therapy versus desmopressin therapy in the treatment of primary mono-symptomatic nocturnal enuresis: a systematic review. Prim Health Care Res Dev 2015;16:21-31.

29. Önol FF, Guzel R, Tahra A, Kaya C, Boylu U. Comparison of long-term efficacy of desmopressin lyophilisate and enuretic alarm for monosymptomatic enuresis and assessment of predictive factors for success: a randomized prospective trial. J Urol 2015;193:655-61.

30. Neveus T, Eggert P, Evans J, et al. Evaluation of and treatment for monosymptomatic enuresis: a standardization document from the International Children's Continence Society. J Urol 2010;183:441-7.

31. Glazener CM, Evans JH. Desmopressin for nocturnal enuresis in children. Cochrane Database Syst Rev 2002;(3):CD002112.

32. Kwak KW, Lee YS, Park KH, Baek M. Efficacy of desmopressin and enuresis alarm as first and second line treatment for primary monosymptomatic nocturnal enuresis: prospective randomized crossover study. J Urol 2010;184:2521-6.

33. Dalrymple RA, Wacogne ID. Gradual withdrawal of desmopressin in patients with enuresis leads to fewer relapses than an abrupt withdrawal. Arch Dis Child Educ Pract Ed 2017;102:335.

34. Rushton HG, Belman AB, Zaontz MR, Skoog SJ, Sihelnik $S$. The influence of small functional bladder capacity and other predictors on the response to desmopressin in the management of monosymptomatic nocturnal enuresis. J Urol 1996;156(2 Pt 2):651-5.

35. De Bruyne P, De Guchtenaere A, Van Herzeele C, et al. Pharmacokinetics of desmopressin administered as tablet and oral lyophilisate formulation in children with monosymptomatic nocturnal enuresis. Eur J Pediatr 2014;173:223-8.

36. Vande Walle J, Rittig S, Bauer S, et al. Practical consensus guidelines for the management of enuresis. Eur J Pediatr 2012;171:971-83. 